\title{
LIMA BARRETO E O VIÉS DO REALISMO POPULAR NA LITERATURA BRASILEIRA
}

\author{
Maria Cristina BATALHA \\ Universidade do Estado do Rio de Janeiro/CNPq \\ cbatalh@gmail.com
}

Resumo: O artigo objetiva mostrar que a ficção de Lima Barreto, com sua proposta literária crítica e popular, acena esteticamente para um viés inexplorado na representação realista da realidade brasileira, em continuidade à obra Memórias de um sargento de milícias, caminho interrompido pela eclosão da Semana de Arte Moderna em 1922, marcado pelo vanguardismo estético-formal, e que é retomado por Lima Barreto em sua obra. O escritor traz de volta uma tradição realista autenticamente nacional. $\mathrm{Na}$ fase anterior ao movimento de 22, duas posturas se delineavam entre os escritores precursores da Semana: uma postura de exclusão, entendida como rompimento inconteste com a estética tradicional, que acaba por operar a substituição de um modelo por outro; e uma outra, de inclusão, representada pela ficção de Lima Barreto, que é a de incorporação da estética popular e da cultura periférica e suburbana.

Palavras-chave: cultura popular. realismo nacional popular. Cultura periférica.

Abstract: The article aims at showing that Lima Barreto's fiction, with its popular and critical literary project, waves aesthetically to an untrodden path in the realistic representation of Brazilian reality, giving continuation to the work Memórias de um sargento de milícia, a path interrupted by the outbreak of the Modern Art Week in 1922, marked by the formal-aesthetic vanguardism, and which is reassumed by Lima Barreto in his work. The writer brings back a truly national realistic tradition. In the previous phase of the movement 22, two positions were delineated among the forunners of the Week: first, a stance of exclusion, understood as an undeniable breakup with traditional aesthetics, which ultimately operated as the replacement of a model by another, and the second, a position of inclusion, represented by the fiction of Lima Barreto, which is the incorporation of popular aesthetics and of peripheral and suburban culture.

Keywords: popular culture. National popular realism. Peripherical culture.

Nas últimas décadas do século XIX, a corrente realista-naturalista impõe-se na cena literária brasileira, partindo de uma recusa subjetiva do quadro de estagnação social característica do Segundo Império. Se o Realismo se apresenta como uma escolha estética e ideologicamente legítima para aqueles que fazem uma ficção moderna, é preciso lembrar que, de acordo com Georg Lukács (1965), não existe oposição entre o Realismo e a inovação formal, mas sim entre tendências realistas e não realistas. Ambas

\begin{tabular}{|l|l|l|l|l|}
\hline Pensares em Revista & São Gonçalo, RJ & n. 1 & $51-65$ & jul.-dez. 2012 \\
\hline
\end{tabular}


são possibilidades diferentes de colocar em relação modos de significar e significados, pois se trata de uma estrutura de relacionamento entre objetos representados e suas formas de representação. Assim, no plano objetivo da produção artística, o nosso Realismo-Naturalismo responde à imobilidade social reinante, ao considerar os desvios do comportamento humano como alguma coisa de permanente e inexorável. É nesse contexto que a ficção de Lima Barreto, com sua proposta literária afetiva e popular, acena esteticamente para um viés inexplorado na representação realista da realidade brasileira. Lima pode ser considerado um precursor de um modelo ficcional que coloca em primeiro plano a periferia, com seus personagens, suas mazelas e potencialidades humanas, sem o glamour das visões romanticamente idealizadoras.

Retomando o conceito de "intimismo à sombra do poder", conceito vinculado ao de "via prussiana", isto é, uma leitura do papel do intelectual numa sociedade onde o reformismo social é feito pelo alto, amplamente utilizado por Georg Lukács em suas análises do célebre ensaio, "Grandeza e sofrimento de Richard Wagner" (1965), de Thomas Mann, Carlos Nelson Coutinho observa que, na formação da sociedade brasileira,

\footnotetext{
$\mathrm{O}$ "intimismo à sombra do poder" combinou-se frequentemente com um inconformismo declarado, com um mal-estar subjetivamente sincero diante da situação social dominante. O que determina os limites do "intimismo à sombra do poder", em última instância, é o fato de que ele capitula diante dos preconceitos ideológicos gerados espontaneamente pela "via prussiana", ou seja, por um lado, o subjetivismo extremado que vê nos indivíduos excepcionais as únicas forças da história, e, por outro, o fatalismo pseudo-objetivo que amesquinha ou dissolve o papel da ação humana na criação da história. Facilmente se perceberá que esses dois preconceitos, no plano estético, dão origem respectivamente ao romantismo e ao naturalismo (COUTINHO, 1972, p. 5).
}

A citação é longa, porém, ela se justifica por dois motivos: primeiramente, por expressar uma homenagem ao grande pensador marxista brasileiro, que nos deixou recentemente; em segundo lugar, pelo fato de que a visão do crítico se apresenta como um norte a guiar a nossa reflexão sobre o lugar e o papel de Lima Barreto na série literária brasileira, pontuando o tipo de realismo praticado pelo escritor. Circulando em espaço paralelo ao do circuito oficial das academias, sem apadrinhamento literário, Lima deixa em suas crônicas, artigos e em sua literatura de ficção as marcas de uma

\begin{tabular}{|l|l|l|l|l|}
\hline Pensares em Revista & São Gonçalo, RJ & n. 1 & $51-65$ & jul.-dez. 2012 \\
\hline
\end{tabular}


trajetória sofrida e problemática, mostrando, sem o pudor das grandes cabeças pensantes da época, as fissuras sociais de uma sociedade extremamente desigual. Como chama a atenção Carlos Nelson Coutinho, enquanto o modernismo ousado de Oswald de Andrade tornava-se o precursor da vanguarda brasileira, ou seja, uma das "versões avançadas" do velho "intimismo à sombra do poder", Lima Barreto trazia de volta uma vertente inaugurada pelas Memórias de um sargento de milícias, narrativa épica de Manuel Antônio de Almeida, retomando a linha do realismo crítico nacional-popular na literatura brasileira (COUTINHO, 1972, p. 55).

Se o movimento da Semana de 22 estava sendo gestado por alguns escritores cujas obras já representavam uma fissura no bloco realista-naturalista, predominante na literatura brasileira nos fins do século XIX e início do XX, a ruptura com essa ficção perde seu fôlego após as campanhas abolicionista e republicana e dilui-se no que Afrânio Peixoto definiu por "sorriso da sociedade" (PEIXOTO, 1972, p. 5). Esse movimento favorece o surgimento de escritores que os críticos classificam de prémodernistas - designação temporal que nem sempre corresponde à conceituação estética -, abrindo caminho para a eclosão da estética modernista, cujo marco se situa na Semana de 22. Entretanto, o afã de encontrar o perfil de um "nacional" específico que mobilizou os artistas modernistas, deixava supor a existência de uma realidade utópica, unificada e homogênea. Essa concepção mimética sugeria que, ao representar um aspecto da nossa realidade, metonimicamente, estaríamos representando um todo. $\mathrm{O}$ viés apontado inscreve-se numa linha de continuidade com o nosso Naturalismo, que herda a ênfase romântica no plano estilístico e, sobretudo, a vertente temática que prioriza o pitoresco e o exótico.

Em uma espécie de contramão, o realismo de Lima inclina-se para um caminho do Realismo-Naturalismo, aberto pela ficção de Manuel Antônio de Almeida - e posteriormente abandonado até pelos chamados grandes mestres do RealismoNaturalismo -, encenando esteticamente outras alternativas democráticas do povo brasileiro, trazendo à tona o subúrbio carioca com suas imensas potencialidades humanas e culturais, que se contrapunham aos modelos oferecidos pela "via prussiana" dominante. A sutil ironia machadiana foi então substituída pela amarga sátira contra os poderosos, crítica ferina que não hesitou em transformar-se em um impiedoso sarcasmo. Como diz o próprio Lima Barreto,

\begin{tabular}{|l|l|l|l|l|}
\hline Pensares em Revista & São Gonçalo, RJ & n. 1 & $51-65$ & jul.-dez. 2012 \\
\hline
\end{tabular}


Mandei [para publicação] as Recordações do Escrivão Isaías Caminha, um livro desigual, propositalmente mal feito, brutal, por vezes, mas sincero sempre (...). [Ele] tenciona dizer aquilo que os simples fatos não dizem, de modo a esclarecê-los melhor, dar-lhes importância, em virtude do poder da forma literária, agitá-los porque são importantes para o nosso destino. Querendo fazer isso e fazendo compreender aos outros que há importância na questão que eles tratam com tanta ligeireza, não me afastei da literatura conforme a concebo (BARRETO apud COUTINHO, 1972, p. 26).

Nesse sentido, Lima Barreto traz de volta uma tradição realista autenticamente nacional, esquecida em prol de um vanguardismo estético-formal.

Considerando então esse contexto, nossa hipótese é a de que havia na fase anterior ao movimento de 22 , duas posturas que se delineavam entre os escritores precursores da Semana de 22: uma postura de "exclusão", entendida como rompimento inconteste com a estética tradicional, mas que acaba por operar a substituição de um modelo por outro; e uma outra, de "inclusão", representada pela ficção de Lima Barreto, que é a de incorporação da estética popular e da cultura suburbana, esquecidas, mais tarde, pelos modernistas, que privilegiaram aquilo que fora designado canonicamente como "genuíno" ou "primitivo" na cultura brasileira, tais como o índio, o folclore africano e sertanejo, deixando de lado o subúrbio das grandes cidades com sua cultura peculiar e suas propostas contraditórias - e nem por isso ilegítimas - para um projeto de nação.

Parece-nos que somente hoje, dentro da perspectiva de reconhecimento da pluralidade de culturas, da eliminação das fronteiras entre alta e baixa literatura e da apropriação da estética popular pela ficção latino-americana dos anos 70-80, resgata-se um veio que já estava presente na literatura brasileira e que tinha ficado esquecido e neutralizado pela força da proposta modernista.

Ao apontar em Lima Barreto traços que foram abandonados pelo Modernismo, e que, hoje, a nossa ficção contemporânea traz à baila, estamos nos afinando com a reflexão de Silviano Santiago, quando este sugere que "talvez o verdadeiro pós possa se nutrir convenientemente do pré, e não do modernismo propriamente dito" (SANTIAGO, 1989, p. 88).

\section{O Pré-Modernismo: as perspectivas da inclusão e da exclusão}

\begin{tabular}{|l|l|l|l|l|}
\hline Pensares em Revista & São Gonçalo, RJ & n. 1 & $51-65$ & jul.-dez. 2012 \\
\hline
\end{tabular}


A rápida evolução da economia, resultante da vinda da família real portuguesa e da abertura dos portos, enriqueceu substancialmente a vida social da cidade. O Rio de Janeiro iria assistir a um acelerado processo de modernização: ruas iluminadas, bondes elétricos, abertura de teatros que abrigavam as temporadas líricas de companhias europeias, criando uma nova sociabilidade urbana e cosmopolita, onde novos hábitos iriam conviver, às vezes conflituosamente, com antigos costumes de tradição colonial, como nos mostram as obras de Machado de Assis.

Os escritores brasileiros afinam-se com este novo ideário de progresso do final do século, colocando sua pena e sua ciência a favor da construção da nação brasileira, consoante com os ideais de progresso e garantindo sua participação efetiva na modernização do país. Contudo, o país ingressava na era capitalista sem ter os impasses históricos decorrentes da "via prussiana" resolvidos; no plano estético, se Memórias de um sargento de milícias (1852) situa-se em uma época em que a mobilidade social ainda parecia tornar-se uma possibilidade concreta, ou seja, na época imediatamente posterior à Independência política, agora, o "distanciamento" machadiano, segundo Carlos Nelson Coutinho, "ganha a fisionomia de pose aristocrática, ao ser esvaziada da universalidade histórico-humana que assumia" (COUTINHO, 1972, p. 15). Depois de Machado, o formalismo parnasiano domina quase inteiramente o romance brasileiro da época, restaurando a continuidade que efetivamente ocorre na literatura brasileira, ou seja, a continuidade anti-realista do "intimismo à sombra do poder".

Assim, como aponta muito bem Roberto Schwarz (1988), o advento do Realismo, e de seu correlato Naturalismo, não correspondeu entre nós, no plano da ficção, às transformações de ordem econômica e social, como no caso europeu ${ }^{1}$. Essa posição é igualmente endossada por Alfredo Bosi, que coloca essa defasagem como causa do marasmo criativo que se situa entre o boom naturalista e a Semana de 22:

Não havia no Brasil do começo do século aquela espessura cultural que faz do fenômeno artístico um encontro permanente de significados sociais, existenciais e propriamente estéticos. Tomavamse de empréstimo atitudes, formas de pensamento e de estilo, na falta de uma percepção radicalmente nova do real (BOSI, 1986, p. 221) (Grifos do autor).

\footnotetext{
${ }^{1}$ Cf. a esse respeito Coutinho (1972, p. 265), que adverte que o mesmo descompasso não ocorre com o Modernismo, que representa um movimento nascido das necessidades internas da intelectualidade brasileira, o que não impede, por outro lado, sua aproximação com os movimentos de vanguarda europeia, retirando, a partir desse contato, uma elaboração pessoal e bastante original.
}

\begin{tabular}{|l|l|l|l|l|}
\hline Pensares em Revista & São Gonçalo, RJ & n. 1 & $51-65$ & jul.-dez. 2012 \\
\hline
\end{tabular}


Desse modo, o projeto realista-naturalista estava longe de ser coeso e, desde cedo, apresenta suas fissuras, engendradas pelo descompasso em relação à nossa realidade. Além das divergências mais profundas que dividiam os intelectuais com relação aos novos valores correntes após a implantação da República, que opunham, por exemplo, Lima Barreto e Euclides da Cunha, de um lado, a Afrânio Peixoto e Coelho Neto, de outro $^{2}$, havia igualmente uma outra fissura, mais sutil, que colocava os dois primeiros em campos opostos quanto ao projeto social e estético que os movia. Embora, como destaque Nicolau Sevcenko (1989), ambos os escritores, Lima e Euclides, tenham sido formados na escola positivista e tenham tido a visão de uma sociedade cosmopolita humanitária, assentada sobre o princípio do evolucionismo progressista liberal, como herança dos valores iluministas, eles tenham percebido igualmente a incompatibilidade desse projeto com a expansão desordenada do capitalismo.

Porém, se tanto Lima Barreto quanto Euclides da Cunha traziam à tona a questão nacionalista e mostravam empenho em dirigir suas reflexões para o Brasil, voltando às costas para a Europa, a forma como cada um deles estava inserido no universo da nova ordem republicana iria determinar uma visão de mundo particular e colocá-los, sob vários aspectos, em lados antagônicos. Basicamente suas divergências vão repousar sobre questões pertinentes aos conceitos de ciência, raça e civilização. Enquanto Euclides aposta no valor incondicional da ciência, Lima vai situá-la como fonte de preconceito, dando sustentação à teoria das raças - veiculada na Europa por Hippolyte Taine e Ernest Renan - que, aliada a um tipo de civilização ideal calcada no modelo europeu, vai informar uma organização social e política brasileira, alinhada com os valores e crenças da Europa hegemônica.

Diante do fato político representado pela República, colocava-se a questão do caminho a seguir e do tipo de sociedade que se queria construir: ou bem o Brasil afinava seu passo com o progresso e se alçava ao padrão europeu, excluindo nesse modelo de civilização os menos favorecidos, os negros e os incapazes ${ }^{3}$; ou bem, como postulava

\footnotetext{
${ }^{2}$ A fase que antecedeu o Modernismo coloca duas correntes radicalmente opostas: os arcaizantes, presos aos cânones consagrados; e os precursores, que, de algum modo já preparavam o terreno para as profundas modificações que o Modernismo iria operar (COUTINHO, 1972, p. 259).

${ }^{3}$ O Barão do Rio Branco, Ministro das Relações Exteriores, seria o grande articulador desse projeto de Nação, que terminou por impor-se completamente, e que, em certo sentido, foi o que vigorou até pouco tempo.
}

\begin{tabular}{|l|l|l|l|l|}
\hline Pensares em Revista & São Gonçalo, RJ & n. 1 & $51-65$ & jul.-dez. 2012 \\
\hline
\end{tabular}


Lima Barreto, a construção de uma Nação desenvolvida passava, em primeiro lugar, pelo princípio da inclusão, i.e., primeiro seria necessário eliminar as diferenças entre paulistas e o resto do país (BARRETO, 1995), entre negros e brancos e entre pobres e ricos, para, assim, acertarmos o nosso passo com o progresso verdadeiro.

Falando do ponto de vista do excluído, do negro, do pobre, do suburbano, do louco e do prisioneiro, a ficção de Lima Barreto traz à baila noções como progresso, originalidade e vanguarda cultural, questionando a necessidade do novo a qualquer preço. No plano narrativo, esses temas são desmistificados e seus conteúdos são colocados sob a ótica da relativização; no plano do discurso, a desconstrução e o esvaziamento se operam pela ambiguidade que se instala do ponto de vista do narrador, que mantém com o protagonista uma relação que oscila entre a adesão e o afastamento crítico; no plano estético, o questionamento se expressa pela apropriação dos recursos da escrita folhetinesca enquanto produção voltada para o consumo popular, o que evidencia a preocupação de Lima em incluir leitores marginalizados pela cultura erudita.

\section{Triste fim de Policarpo Quaresma: a perspectiva da inclusão}

A narrativa de Lima Barreto transita pelos planos da ficção, da História e da autobiografia que, conjugados, alimentam uma literatura que incita a reflexão, propiciando a desconstrução do discurso oficial, endossado de certa forma pelos Naturalistas, e calcado em um modelo de sociedade, na qual modernização e autoritarismo se associam para excluir aqueles que não se encaixam nos novos valores impostos pela República Velha. Sua ficção traz à cena o subúrbio carioca, com suas manifestações populares, sua linguagem e seus padrões de comportamento próprios. Ao lado do subúrbio, espaços igualmente marginalizados como o do hospício e o da prisão, com seus personagens desprestigiados socialmente e deslocados do universo da razão, da ordem e do poder, compõem a atmosfera na qual vai se desenvolver a narrativa de Lima. Triste fim vai tematizar questões como a repressão sofrida pelo intelectual dissidente, a violência do manicômio e do sistema carcerário, o autoritarismo subjacente às regras do poder, passando pela crítica ao arrivismo e à prática do favor tão arraigada

\begin{tabular}{|l|l|l|l|l|}
\hline Pensares em Revista & São Gonçalo, RJ & n. 1 & $51-65$ & jul.-dez. 2012 \\
\hline
\end{tabular}


entre nós, prática correlata da "via prussiana", que atinge também a intelectualidade brasileira, engendrando a postura do "intimismo à sombra do poder".

O modelo de cidade que se quer impingir como "moderna" implica a reorganização do espaço urbano no sentido do afastamento das "classes perigosas" em direção à periferia, deixando livre o "cartão postal" que seria apresentado aos visitantes estrangeiros que, por sua vez, forneciam o modelo de civilização a ser imitado. Inseremse nesse projeto as obras de reurbanização do Rio de Janeiro levadas a cabo pelo prefeito Pereira Passos, o nosso barão Haussmann, bem como, posteriormente, a derrubada do Morro do Castelo, efetuada sob a administração de Carlos Sampaio (19201922), fato que gerou enorme polêmica e agitou a imprensa da época (RESENDE, 1993, p. 51). Fazia parte do mesmo processo de "limpeza" da cidade, o alijamento das marcas culturais que denunciavam a presença do negro, do pobre, do louco e do suburbano, enfim, de todos aqueles que tinham sido deixados de fora da "modernização". Por isso, a "modinha", manifestação popular, estava excluída do universo familiar das pessoas "sérias", o que impediu que Ricardo Coração dos Outros fosse convidado para a festa de noivado de Ismênia. Assim, comenta Beatriz Resende:

Em 1888, durante o Império, o povo saía às ruas para comemorar com festejos populares que duraram uma semana. Diz Lima Barreto: 'jamais em minha vida, vi tanta alegria. Era geral era total'. No ano seguinte os festejos se repetiram. No entanto, ainda segundo o cronista, no mesmo texto 'veio a República, e logo as novas autoridades acabaram com aquela folgança de mês" (RESENDE, 1993, p. 39).

Da mesma forma, a "modernização" impunha o controle da desordem e um processo de "higienização" como seu correlato, o que vai colocar a família nuclear urbana como elemento decisivo para a saúde social, elegendo o saber médico como agente ordenador do social ${ }^{4}$. Acertar o passo com a Europa modernizada exigia a adoção de novas práticas de higiene, controladas pelo Estado, entre as quais a campanha da vacinação obrigatória poderia figurar como um exemplo do tipo de política implantada de cima para baixo, sem levar em conta as diferentes motivações e anseios que moviam os diversos segmentos sociais.

\footnotetext{
${ }^{4}$ Cf. a esse respeito, Muricy (1988).
}

\begin{tabular}{|l|l|l|l|l|}
\hline Pensares em Revista & São Gonçalo, RJ & n. 1 & 51-65 & jul.-dez. 2012 \\
\hline
\end{tabular}


$\mathrm{Na}$ perspectiva da asseptização da vida social, todo aquele que fugia à norma estava automaticamente excluído, como o louco, o doente e o solteiro (Ismênia, por exemplo): "Não é só a morte que nivela; a loucura, o crime e a moléstia passam também a sua rasoura pelas distinções que inventamos" (BARRETO, 1994, p. 64), diz o narrador de Triste fim. Com relação à loucura, o autoritarismo da razão, associado ao autoritarismo político, cassava-lhe o direito à palavra e deixava o louco de fora da comunidade da razão e da ordem. Havia uma barreira separando o espaço do hospício, onde os visitantes "não se olhavam, pareciam que não queriam conhecer-se na rua" (BARRETO, 1994, p. 65), e o espaço da sanidade do lado de fora.

Silviano Santiago chama a atenção para o empobrecimento da visão do cotidiano de uma sociedade, quando se nega o "peso gerador de civilização" constituído pelos excluídos que, na maioria das vezes, são tratados como não-históricos (SANTIAGO, 1981). Neste ponto, a contribuição de Lima Barreto nos parece inestimável, pois, consciente da ausência da massa dos excluídos da ficção brasileira, diz ele através de seu narrador, após descrever o subúrbio com seus moradores pobres e miseráveis: "aí, nesses caixotins humanos, é que se encontra a fauna menos observada da nossa vida" (BARRETO, 1994, p. 84). É ainda sob a ótica da "marginália", que estava fora da representação literária que se fazia da cidade, que Beatriz Resende (1993), em seu interessante estudo da obra de Lima Barreto, procura recompor o retrato da Capital Federal a partir da construção do conceito de cidadania. Durante esse processo, delinease o perfil daqueles a quem se atribui o direito de "cidadão", e nega-se a cidadania a todos os que não se encaixam nesse perfil.

O que norteia a vida de Policarpo Quaresma é seu desejo de transformar em realidade concreta, sustentada por um projeto político, social e econômico, uma certa ideia abstrata de Nação e de Pátria, forjada pelas leituras que fez, e que, por sua vez, repousam em um pensamento autoritário, cujos traços principais são postulados pelo historiador francês Renan. Singular e contraditória ideologia política que apresenta traços marcadamente bizarros. Para Carlos Nelson Coutinho, a bizarrice é a expressão literária proveniente do "profundo realismo do autor" (COUTINHO, p. 35). E, conforme aponta Georg Lukács:

A bizarrice é uma certa adaptação que se faz no interior do sujeito e que decorre das possibilidades de prática social concreta que lhe é

\begin{tabular}{|l|l|l|l|l|}
\hline Pensares em Revista & São Gonçalo, RJ & n. 1 & $51-65$ & jul.-dez. 2012 \\
\hline
\end{tabular}


permitida pela ordem específica da realidade. Mais corretamente: decorre do fato de que, se um homem pode se revelar capaz, em seu foro íntimo, de enfrentar as transformações negativas das formas fenomênicas dadas de uma sociedade (...) de modo tal que sua integridade interior, ameaçada por tais formas, consiga resistir à prova, se isso ocorre, então a conversão dessa recusa numa prática social propriamente dita (conversão que se torna humanamente necessária) não pode ultrapassar - por causa de sua incompatibilidade socialmente determinada - os limites de uma interioridade abstrativa mais ou menos deformante. Disso decorre que o caráter desemboca na excentricidade, na extravagância (LUKÁCS, 1970, p. 122-3).

Assim como Policarpo, todos os outros personagens se afiguram igualmente como descentrados e "bizarros", porque estão deslocados do meio em que vivem, e divididos entre o sonho e a realidade. Atuam como se estivessem presos a uma teia de discursos dados previamente e cujos fios não conseguem romper. Os discursos cristalizados são desconstruídos ao longo do romance e são desmistificados um a um, como, por exemplo, o que define o papel do militar:

O general nada tinha de marcial, nem mesmo o uniforme que talvez não possuísse. Durante toda a sua carreira militar, não viu uma única batalha, não tivera um comando, nada fizera que tivesse relação com a sua profissão e o seu curso de artilheiro. (...) Nada entendia de guerras, de estratégia, de tática ou de história militar; a sua sabedoria a tal respeito estava reduzida às batalhas do Paraguai, para ele a maior e a mais extraordinária guerra de todos os tempos (BARRETO, 1994, p. 31).

Como nos mostra o excerto, pelo viés da ironia, o narrador de Triste fim desfaz a ideia de bravura e heroísmo associados à carreira militar. Da mesma forma, são desconstruídos o mito do brasileiro indolente e preguiçoso, em contraposição ao da terra pródiga e dadivosa:

Aí por depois do meio-dia, quando o calor parecia narcotizar tudo e mergulhar em silêncio a vida inteira, é que o velho major percebia bem a alma dos trópicos, feita de desencontros como aquele que se via agora, de um sol alto, claro, olímpico, a brilhar sobre um torpor de morte, que ele mesmo provocava (BARRETO, 1994, p. 78).

No plano do discurso, a ambiguidade que leva à reflexão instala-se pela presença de um narrador múltiplo, que oscila entre a ironia e a crítica, de um lado, e a adesão aos

\begin{tabular}{|l|l|l|l|l|}
\hline Pensares em Revista & São Gonçalo, RJ & n. 1 & $51-65$ & jul.-dez. 2012 \\
\hline
\end{tabular}


propósitos de Policarpo, do outro. Se este reconhece que o protagonista é um visionário, ao mesmo tempo, admite que seus motivos não são destituídos de lógica. Assim, Policarpo é um produto do discurso oficial e, ao mesmo tempo, um crítico desse mesmo discurso. Em Policarpo, Lima encena ficcionalmente uma implacável crítica àquela sociedade que condena ao ridículo e à bizarrice as mais profundas e legítimas vocações do povo brasileiro, que reivindica para si o direito de intervir nos destinos do país.

Por isso, Coutinho chama a atenção para o significado emblemático dos personagens de Olga e de Ricardo:

\begin{abstract}
O encontro e a ligação desses dois personagens [Olga e Ricardo], simbolizando a aliança entre a "plenitude limitada" das camadas populares e a revolta contra a alienação, não é uma simples casualidade: expressa-se aqui, de modo concretamente estético, a visão de mundo de Lima Barreto. Olga e Ricardo, com efeito, significam para o romancista alternativas concretas à mesquinha atmosfera burocrática que dissolve miseravelmente a humanidade dos homens (COUTINHO, 1972, p. 52).
\end{abstract}

No plano estético, uma das contribuições de Lima Barreto reside na quebra da linguagem oficial academicista e na utilização de uma linguagem despojada, simples, direta e coloquial. Não interessa ao autor transcender pelo desvio poético a banalidade do cotidiano. Como lembra Osman Lins, "entre a elipse que embeleze a frase e a repetição que infunda ao escrito um ar menos composto, [Lima Barreto] prefere em geral esta segunda solução, que preservará a clareza e o natural” (LINS, 1976, p. 20).

Parece estar exatamente aí a grande novidade da escrita de Lima, pois, enquanto a literatura erudita se organiza em torno da diferença e da ruptura estética, a literatura popular organiza-se em torno da repetição e da redundância. A escolha feita pelo autor por uma estética acentuadamente popular, num quadro em que os padrões de legitimação eram fornecidos pela literatura erudita, parece revelar uma tomada de posição em relação ao tipo de leitor para o qual está dirigindo sua produção. Para isso, Lima Barreto vai lançar mão das técnicas folhetinescas que atraem o leitor comum, ou seja, é muito mais pela via da reiteração do que pela da surpresa que esse leitor se prenderá à leitura.

Flora Süssekind (1987), estudando a produção ficcional brasileira do período que se estende entre o final do século XIX e os primeiros anos do século XX, assinala a

\begin{tabular}{|l|l|l|l|l|}
\hline Pensares em Revista & São Gonçalo, RJ & n. 1 & $51-65$ & jul.-dez. 2012 \\
\hline
\end{tabular}


influência que as novas técnicas - fotografia, cinema, cartaz e jornal - exerceram sobre essa produção, sobretudo no que concerne o tipo de público a que estava destinada. Se, para o leitor culto, o que interessa é a novidade, o original e o enigmático, para o leitor pouco familiarizado com a escrita, o que vai prendê-lo à leitura é a confirmação daquilo que está esperando e um narrador que "explique para ele" os eventuais enigmas que o texto possa esconder. A esse respeito, observa Silviano Santiago:

Esquecem-se esses pseudo-escritores populares que o leitor de folhetim ontem, e o espectador de telenovelas hoje, se deixa mais prender pela isca da repetição do que pelo anzol da surpresa. O leitor comum tem o seu interesse aguçado pela redundância que explicita, na repetição de uma cena ou de um diálogo, o que muitas vezes não ficou claro na dramatização (SANTIAGO, 1989, p. 90).

Ao recusar a elipse e ao adotar os recursos característicos da escrita folhetinesca, sem contudo reduzir sua ficção a apenas isso, Lima Barreto revela a preocupação de ampliar o público leitor, integrando leitores que estariam normalmente excluídos do círculo da literatura erudita, apontando para a possibilidade de um modelo realista de viés nacional e popular.

O crítico Sérgio Buarque de Holanda, refletindo sobre a obra do autor do ponto de vista do Modernismo, atribui a ela um valor de sinceridade pelo caráter confessional que a norteia, mas lamenta a ausência de "pesquisa formal" e de "originalidade", postulados que se constituem em verdadeiras vias de acesso à estética modernista. Diz ele: "essa arte não denuncia a menor preocupação com as técnicas que servissem para enriquecê-la ou renová-la". E, continua: "Lima Barreto limita-se quase sem exceção, a pôr em prática, fiado no talento que Deus lhe deu e que os desenganos da vida apuraram, as tradicionais convenções da novela realista" (HOLANDA, 1978, p. 138).

Parece-nos evidente que, da perspectiva de exclusão de uma determinada estética popular assumida pelo Modernismo, a escrita de Lima possa parecer "pobre" e "redundante". Rompido com os "mandarins" da literatura e situado à margem da sociedade letrada que dominava a produção intelectual da época - tanto o mercado editorial quanto o jornalístico -, Lima Barreto é levado a escrever em pequenos jornais, em geral de oposição ao regime, e consegue, assim, preservar sua independência, trilhando o caminho da contramão da literatura dominante (RESENDE, 1993, p. 23),

\begin{tabular}{|l|l|l|l|l|}
\hline Pensares em Revista & São Gonçalo, RJ & n. 1 & $51-65$ & jul.-dez. 2012 \\
\hline
\end{tabular}


retomando o viés do realismo popular que havia sido aberto por Manuel Antônio de Almeida e abandonado posteriormente. Como sugere Carlos Nelson Coutinho,

Com Lima Barreto, iniciou-se para a literatura brasileira uma nova etapa - moderna e popular - do realismo. Tanto em sua obra estética quanto em sua produção jornalística, o romancista carioca rompe decisivamente com qualquer versão do "intimismo à sombra do poder", colocando com grande clareza a dimensão social e humanista do ofício literário. Diante de todas as questões que enfrentou, como escritor ou periodista, Lima sempre tentou encontrar (e na esmagadora maioria dos casos efetivamente encontrou) uma resposta autenticamente democrática e popular, capaz de abrir novos horizontes - ideológicos e estéticos - para a cultura e para a arte de nosso país (COUTINHO, 1972, p. 54).

A multiplicidade de narradores cujas facetas se entrecruzam no texto, a linguagem solta e despojada, a incorporação da linguagem e das técnicas do jornal pela sua literatura, assim como a reflexão crítica que ela suscita, anunciam e preparam o terreno para a eclosão do movimento Modernista que, no entanto, deixará de lado alguns dos aspectos aqui apontados, e informará sua estética numa perspectiva de vanguardismo, afastando de seu âmbito um público menos afeito às ousadias formais que o movimento instaura. Parece-nos que o interesse suscitado posteriormente pela obra de Lima Barreto, encontra ressonância em um tipo de literatura que visa a restabelecer o elo perdido com o público, distanciado pelo hermetismo em que o movimento modernista se encerrou. O viés crítico do realismo de cunho popular proposto por Lima Barreto traz para a cena literária brasileira a leitura da realidade da "vida como ela é...".

\section{Referências bibliográficas:}

ATHAYDE, Tristão de. Macunaíma. In: Vida literária. O Jornal, Rio de Janeiro, 09 de setembro, de 1928, p. 4.

BARRETO, Lima. Triste fim de Policarpo Quaresma, 12. ed. São Paulo: Ática, 1994. República dos Bruzundangas. São Paulo: Ática, 1995 [1922].

BOSI, Alfredo. História concisa da literatura brasileira. 3. ed. São Paulo: Cultrix, 1986.

Dialética da colonização. São Paulo: Companhia das Letras, 1992.

\begin{tabular}{|l|l|l|l|l|}
\hline Pensares em Revista & São Gonçalo, RJ & n. 1 & $51-65$ & jul.-dez. 2012 \\
\hline
\end{tabular}


BUENO, André. Visões do paraíso perdido. In: Perspectivas 3, Rio de Janeiro, n. 3, UFRJ, 1988.

COUTINHO, Afrânio. Introdução à literatura no Brasil. 7. ed. Rio de Janeiro: Editora Distribuidora de Livros Escolares, 1972.

COUTINHO, Carlos Nelson. O significado de Lima Barreto na Literatura Brasileira. In: Realismo e anti-realismo na Literatura Brasileira. Rio de Janeiro: Paz e Terra, 1972, pp. 1-74.

HELENA, Lúcia. Mário e Oswald: identidade e diferença. In: Revista de Letras, Rio de Janeiro, ano 4, n. 4, 1978.

HOLLANDA, Heloisa Buarque de. Pós-Modernismo e política. Rio de Janeiro: Rocco, 1991.

HOLANDA, Sérgio Buarque de. Em torno de Lima Barreto. In: Cobra de vidro. São Paulo: Perspectiva; Secretaria de Cultura, Ciência e Tecnologia do Estado de São Paulo, 1978, pp. 131-146.

LINS, Osman. Lima Barreto e o espaço romanesco. São Paulo: Ática, 1976 (Coleção Ensaios, 20).

LUKÁCS, Georg. Ensaios sobre literatura. Rio de Janeiro: Civilização Brasileira, 1965.

Soljenistsyne. Paris: Seuil, 1970.

MURICY, Katia. A razão cética. São Paulo: Companhia das Letras, 1988.

RESENDE, Beatriz. Lima Barreto e o Rio de Janeiro em fragmentos. Rio de Janeiro: Editora UFRJ; Campinas, SP: Editora UNICAMP, 1993.

PEIXOTO, Afrânio. Panorama da Literatura Brasileira. São Paulo: Editora Nacional, 1972.

RODRÍGUEZ, Selma Calasans. Paródia: triunfo da modernidade. Perspectivas 3, Rio de Janeiro, n. 3, UFRJ, 1988.

SANTIAGO, Silviano. O entre-lugar do discurso latino-americano. In: Uma literatura nos trópicos. São Paulo: Perspectiva, 1978 (Coleção Debates, 155). ago. 1981.

As ondas do cotidiano. $33^{a}$ Reunião Anual da SBPC, Rio de Janeiro, EDIPUC, . Uma ferroada no peito do pé. Rio de Janeiro: EDIPUC, ago. de 1981. 
. Vale quanto pesa. Rio de Janeiro: EDIPUC, mar. de 1982.

Fechado para balanço: sessenta anos do Modernismo. In: Nas malhas da letra. São Paulo: Companhia das Letras, 1989.

SCHWARZ, Roberto. Ao vencedor as batatas. São Paulo: Duas Cidades, 1988.

SEVCENKO, Nicolau. Literatura como missão. 3. ed. São Paulo: Brasiliense, 1989 [1983].

SOUZA, Eneida Maria. Sujeito e identidade cultural. In: Traço crítico. Rio de Janeiro: Editora UFRJ; Belo Horizonte: Editora UFMG, 1993, pp. 13-22.

SÜSSEKIND, Flora. Cinematógrafo de letras. São Paulo: Companhia das Letras, 1987.

Artigo recebido em: 05 de novembro de 2012.

Artigo aprovado em: 15 de novembro de 2012.

\section{Sobre a autora:}

Doutora em Literatura Comparada (UFF/2003) e Mestra em Literaturas de Língua Portuguesa (PUC-Rio/1995). Bolsista de Produtividade do CNPq e do Programa Prociência. É professora adjunta do Instituto de Letras da UERJ. Na Pós-Graduação, atua na linha de pesquisa "Literatura portuguesa e outras literaturas". Integra o GT "Vertentes do Insólito Ficcional", da ANPOLL. 